\title{
Leading Through the Enrollment Cliff of 2026 (Part II)
}

\author{
Linda L. Campion ${ }^{1}$
}

Accepted: 3 December 2021 / Published online: 13 January 2022

(c) Association for Educational Communications \& Technology 2021

The last time we met in Leading Matters, we discussed the rapidly approaching Enrollment Cliff and its impact on small and mid-tier institutions in Higher Education. In the face of struggling to capture the same level of enrollment just a few years out, institutional leadership needs to strategically plan now and be prepared to make difficult programmatic and recruiting decisions, while simultaneously streamlining and improving services offered to assist students in their academic endeavors. Or do they? What if, in the face of a declining college-age population, leadership instead decided to re-design programs and services that would speak to precollege-aged students and lead them to select their institutions? There is time, after all, to conduct a needs analysis, to evaluate current programs and services and determine their net value. There is time to re-brand and recruit more effectively. There is time to utilize current resources more efficiently, including increased cooperation internally (campus community) and externally (alumni, corporations). This type of planning, however, takes a leader willing to try new methods.

\section{Re-designing Programs}

What would you suggest if you were asked how to improve Freshman Orientation sessions to engage both the students and their families in that program? Would you suggest, smaller groups, a meeting with the Chancellor/President, the addition of translators who could accompany families, or perhaps materials created in the language of the attendees? How would you improve the students' introduction to their department, their Academic Advisor, or their faculty, in general? What summer programs could you design and offer that would assist a student in their successful transition to college while also generating income? High school

Linda L. Campion

CAMPIONL16@ecu.edu

1 East Carolina University, Greenville, NC, USA is not college; how can we increase an incoming student's knowledge of the new demands and rigor, given their developmental stage? How can we provide more resources to our Academic and Faculty Advisors so they, too, could increase their efficiency and the quality of their all-important work?

\section{Increasing Services}

It may seem intuitive that higher education begins decreasing services as we face the Enrollment Cliff, but what if we did just the opposite? To my knowledge, every university knows where most of their applicants reside permanently. At my own institution, we know that over $50 \%$ of each incoming class are First Generation college students and we know that most of our first-time full-time students come to us from West of I-95. Our in-state residency is $91 \%$; with out-of-state at $9 \%$. Reviewing the data on our institutional dashboard we have been watching the population of our White male students decrease while our African American and Hispanic/ Latino female populations increase over the last five years. With this data in mind, can we ride out the enrollment cliff by intentionally designing services that attend to what we know about the students who apply to and attend our institutions? Can we do more, not less?

\section{Increasing our Reach}

As soon as we began to talk about the Enrollment Cliff, leaders at my institution made the decision to devote more resources to recruitment. Again, utilizing our demographic institutional data, we hired and placed recruiters intentionally, including out-of-state locations. Pre-COVID-19 and currently, Pirates Set Sail events were/are held in many locations across our state, including high schools and community colleges. Resources have been poured into Undergraduate Admissions. The Admissions website received a re-design, and we did MORE with LESS. 
My institution will be vying for applicants just like many of my sister institutions. Leaders must make the determination to elicit more from the institutional community, displaying a variety of leadership styles such as authoritative, democratic, coaching (Goleman, 2000), depending on the severity of the moment. This moment is severe for us and many others. Effective enrollment management takes commitment from the entire community at your institution. I hope you are ready to be a leader.

\section{Beyond the Cliff; Leaders, Listen to the Experts}

U.S. Intuitions of Higher Education are not just battling a consistent decline in birth-rate, which is leading to the Enrollment Cliff, we are confronting a new decision-making process embraced by the near college-aged generation. Their belief is that college is too expensive, and they are making alternate decisions. According to ECMC Group, "The proportion of students considering four-year college has decreased by 23 percentage points since May 2020, with fewer than half of teens now planning to pursue that pathway (down to 48 percent from 72 percent)" (ECMC Group, pg. 1). This speaks to the longevity of the Cliff or the possibility that recruitment efforts necessary to the survival of many educational institutions will need to change. Not enough emphasis can be placed on the use of data from the students we are attempting to recruit.

Methodical changes are going to be necessary for many institutions to survive, not just through the Enrollment Cliff, but well beyond. A four-year degree needs to be of value with the recipient of that degree comprehending its value. Colleges and universities are going to have to make very difficult decisions because this financial impact of decreased enrollment along with the financial blow of the pandemic makes a viable recovery very troublesome. Let us see what the experts suggest:

\footnotetext{
High School Juniors Share Insight

Scholarship availability is IMPORTANT

Rank of Institution important

Distance from home - want to attend colleges $4+$ hours away from home

They eliminate the college decision based on total cost

Only $16 \%$ reported receiving personalize communications from colleges - most are generic and from mass mailings

HBCUs and HCIs are most important to Black and Hispanic/Latinx students with household incomes below \%25,000/year. Also, more important for rural as opposed to urban students of color

$60 \%$ surveyed are "hopeful" about their college search; at the time of the survey, however, only $18 \%$ felt prepared

These students prefer to conduct their college research online (55\%); compared to $18 \%$ face to face
}

http://niche.bz/2021SpringJuniorSurvey
ECMCListening to the pre-college students, here are some additional steps our institutions can take to remain on the solid side of the cliff:

Conquering the Cliff

Develop and disseminate engaging and personalized communications!

Begin recruiting/outreach early

Talk to them about location and the length of distance from home; broach the subject

Embrace peer-to-peer recruiting! They like hearing from other students

Analyze and re-design your websites, if necessary! This is an online generation, they rely on it and want to use it

Evaluate your financial aid packaging and scholarship programs

http://niche.bz/2021SpringJuniorSurvey

https://resources.campuslogic.com/blog/we-re-facing-an-enrollmentcliff-here-s-how-we-overcome-it

Our leaders are and will be making decisions related to our institutions and our careers. My suggestion is that we offer our services to analyze, design, and assist with a solution so we can stand strong in higher education!

\section{References}

Goleman, D. (2000). Leadership that gets results. Harvard Business Review, March-April, 78 - 90.

Campus Logic. (n.d.) We're facing an enrollment cliff. Here's how we overcome it. Resources.campuslogic.com. https://resources.campu slogic.com/blog/we-re-facing-an-enrollment-cliff-here-s-how-weovercome-it. Accessed 15 Nov 2021

High School Students Are Uncertain About College. (2021, November 15). ECMCGroup.org. Retrieved November 19, 2021 from https:// www.ecmcgroup.org/news/group/high-school-students-are-uncer tain-about-college

Patch, W. (2021, May 11). 2021 Survey of Juniors Searching for College. Niche.com. https://www.niche.com/about/enrollment-insig hts/2021-survey-of-juniors-searching-for-college/

Publisher's Note Springer Nature remains neutral with regard to jurisdictional claims in published maps and institutional affiliations. 